\title{
Decadal warming of the coldest Antarctic Bottom Water flow through the Vema Channel
}

\author{
Walter Zenk ${ }^{1}$ and Eugene Morozov ${ }^{2}$ \\ Received 11 April 2007; revised 15 May 2007; accepted 6 June 2007; published 26 July 2007.
}

[1] A decadal warming trend of Antarctic Bottom Water flowing through the Vema Channel is reanalyzed. Our data base consists of 94 high precision, full depth stations from 19 visits to the Vema Sill plus twelve stopovers at two additional key locations. Originally a long-term temperature increase in the near-bottom jet was noted from 1992 onward, after a period of rather constant abyssal temperatures since 1972. From today's perspective the apparent stagnant temperature level until 1991 can be interpreted as a period of feeble rising in comparison with a perspicuous warming trend of $2.8 \mathrm{mK} \mathrm{yr}^{-1}$ in the following 15 years. However, the clearly manifested temperature rise is superimposed with fluctuations. For the first time the available time series appears long enough to indicate an associated slight freshening of the bottom water. An attempt is made to trace the observed variability back to its source region in the Weddell Sea. Citation: Zenk, W., and E. Morozov (2007), Decadal warming of the coldest Antarctic Bottom Water flow through the Vema Channel, Geophys. Res. Lett., 34, L14607, doi:10.1029/2007GL030340.

\section{Introduction}

[2] Antarctic Bottom Water (AABW) represents the coldest and deepest layer of the western South Atlantic. More than half a century ago this watermass had been traced back to its source regions in high latitudes of the Southern Ocean. A commonly accepted definition describes AABW as water with potential temperature $(\theta)$ cooler then $2^{\circ} \mathrm{C}$. Since the beginning of the World Ocean Circulation Experiment (WOCE) in early 1991 sustained observations of AABW characteristics and transports have been conducted at selected sites around the Brazil Basin. One of the WOCE core projects was focused on the role of deep passages which allow an equatorward interbasin exchange of AABW (Figure 1). The Vema Channel with its sill depth of over $4600 \mathrm{~m}$ at $\sim 31^{\circ} \mathrm{S}, \sim 39^{\circ} \mathrm{W}$ represents a choke point for abyssal circulation between the Argentine Basin in the south and the Brazil Basin farther downstream.

[3] The implication of abyssal pathways for the global thermohaline circulation and ventilation, and the role of $\mathrm{AABW}$ in interhemispheric exchange have turned the Vema Channel with its easy accessibility into a privileged spot for continued observations beyond the end of the WOCE decade. The ongoing motivation for numerous revisits (by

\footnotetext{
${ }^{1}$ Leibniz Institute of Marine Sciences at the University of Kiel (IFMGEOMAR), Kiel, Germany.

${ }^{2}$ Shirshov Institute of Oceanology, Moscow, Russia.
}

Copyright 2007 by the American Geophysical Union. 0094-8276/07/2007GL030340 now 19) (for details, see auxiliary material Table $\mathrm{S} 1^{1}$ ) is maintained by a general decadal warming trend in the AABW that was first noted by Zenk and Hogg [1996]. Due to the small magnitude of the expected signals the detection of significant changes in bottom water properties requires modern techniques with highest accuracy and stability.

[4] For the first time the length and accuracy of CTD (conductivity, temperature, depth) time series from the Vema Channel appear sufficient to allow also for an analysis of the associated salinity (S) record. The latter appears to be anti-correlated with the observed decadal temperature rise. In fact, this result implies a long-term trend towards decreased density of abyssal waters in the Vema Channel and possibly in the whole deep western South Atlantic.

[5] As comparable studies show, it is difficult to isolate a trend in spatially and temporally aliased shorter series. As an example, Fukasawa et al. [2004] found a general warming of the deep Pacific along $47^{\circ} \mathrm{N}$ between $140^{\circ} \mathrm{E}$ and $120^{\circ} \mathrm{W}$ which is negatively correlated with salinity changes in the depth range 500-3000 m. However, below $5000 \mathrm{~m}$ they also report a basin-wide warming of $5 \mathrm{mK}$ (millikelvin) in 14 years, but with "no significant change in the salinity field". They applied the conservative detection limit of 0.003 in salinity.

[6] Since reliable estimates for the robustness of the interoceanic thermohaline circulation are rare, the identification of such long-term changes of deep water mass characteristics is of particular interest. They are needed as observational constraints in ocean circulation models. The objective of this note is to describe the evolution of the abyssal warming phenomenon in the Vema Channel in the light of the historic database, and recent site visits one decade after the last progress report by Hogg and Zenk [1997]. Thanks to annual visits of the Russian research vessels "Akademik Ioffe" and "Akademik Sergey Vavilov" en-route to Antarctica since 2002 new data are now available on the variability of AABW through the channel.

\section{Topography and the Data Set}

[7] The investigated area and geographic names are shown in Figure 1. A virtual "pipeline" for AABW with its highest density in the whole water column crosses the Rio Grande Rise. North of its entrance on the Argentine side the Vema Channel depth contours follow an almost meridional direction. At its shallowest spot, the Vema Sill measures $4646 \mathrm{~m}$ in depth at a width of roughly $15 \mathrm{~km}$. Seen from the bottom, the canyon-like side walls on both

\footnotetext{
${ }^{1}$ Auxiliary material data sets are available at $\mathrm{ftp}: / / \mathrm{ftp}$. agu.org/apend/g1/ 2007gl030340. Other auxiliary material files are in the HTML.
} 


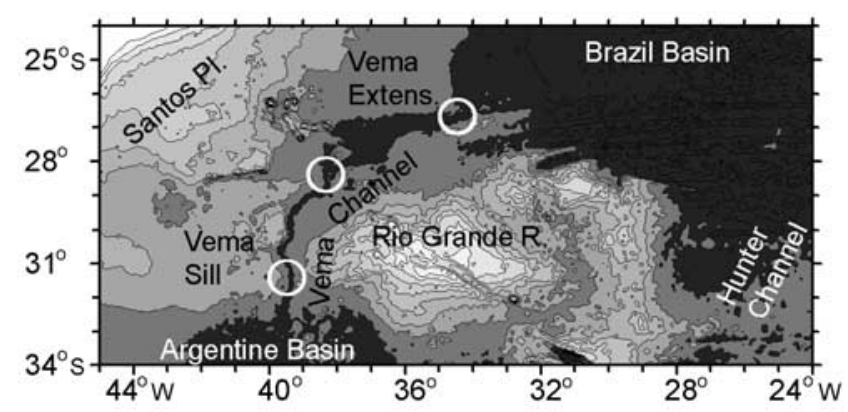

Figure 1. Topography of the Vema Channel in the South Atlantic. Note the three locations with large circles in the south-to-north flow direction: Vema Sill, Santos Plateau mouth, Vema Extension. They indicate the source regions of the data sets used here. The canyon limited by the deepest isobath at $4500 \mathrm{~m}$ acts as a "pipeline" for the coldest Antarctic Bottom Water (AABW).

sides of the saddle point at $31.2^{\circ} \mathrm{S}$ are about $600 \mathrm{~m}$ high [Zenk et al.,1993]. Since 1991 the majority of revisits with CTD casts concentrated on a narrow strip at that latitude (southern circle in Figure 1). Following the Vema Channel equatorward, the pathway of $\mathrm{AABW}$ extends and broadens slightly farther northward of $29^{\circ} \mathrm{S}$. Here the dense bottom water that has already crossed the lower Santos Plateau to the west merges with bottom water in the Vema Channel. AABW then flows northeastward through a buffering reservoir at $27^{\circ} \mathrm{S}$. Hereafter it can leave the Vema Channel. Before the confined contour current finds its exit after about $900 \mathrm{~km}$ in an easterly direction into the deep Brazil Basin $(>5000 \mathrm{~m})$ it has to pass an unnamed deep narrow passage at about $27^{\circ} \mathrm{S}, 34^{\circ} \mathrm{W}$ for which we suggest the working title Vema Extension (northern circle in Figure 1). All together we have compiled 94 CTD stations from 19 revisits to the Vema Channel. The first eleven successful visits to the sill region were already evaluated in the earlier work of Hogg and Zenk [1997].

[8] In the beginning of the time series (1972-1990) satellite supported navigation was not permanently available on research vessels with today's high accuracy. The local topography was less well known. Hence, CTD casts were taken in a wider range south and north of the exact location of the sill (for details, see auxiliary material Figure S1). Since 1991 the lowest temperatures on all repeated sections were encountered consistently on the eastern half of the sections across the Vema Sill [Hogg and Zenk, 1997]. This phenomenon reflects the frictionally induced thick bottom boundary layer on the right side of the throughflow jet in the southern hemisphere. The concurrent secondary or helical circulation sharpens the interface above the mixed bottom layer. It causes the well-known isotherm pinching in the vertical temperature distribution [Johnson and Sanford, 1992; Jungclaus and Vanicek, 1999].

[9] Data accuracy and stability are important issues for all long-term observations. In case of CTD casts we see a steady technical improvement since the breakthrough of these systems in modern oceanography. The data we have analyzed had been obtained either with Neil Brown instruments or-in the last decade-SeaBird instruments. In the search for systematic trends in abyssal bottom temperatures in the Weddell Sea, Robertson et al. [2002] also faced uncertainties in different cruises similar to our investigation. Therefore, we follow their careful considerations and compile our outcome in Table 1. Triggered by the demand for high calibration standards during the WOCE decade 19902000 , the accuracy of high quality CTD data nowadays has leveled at $(2 \leq|\Delta \theta| \leq 3) \mathrm{mK}$ for potential temperature and $\Delta \mathrm{S} \sim \pm 0.003$ in salinity. Absolute pressure uncertainties for deep-sea sensors are expected to lie below \pm 3 dbar. During most expeditions to the Vema area pre- and post-cruise calibration checks of the operated CTD probes were performed. Near-bottom salinity data from at least two different rosette samplers were ranked as the highest reference for calibration checks. Fortunately we are favored by a growing instrumental stability. It has been improved significantly over the last three decades.

\section{Trends in Potential Temperature and Salinity of the Coldest Bottom Water Along the Vema Channel}

[10] AABW with potential temperatures below $2^{\circ} \mathrm{C}$ (corresponding to a density $\sim 45.85 \sigma_{4}$ ) is not a homogeneous watermass. Occasionally one distinguishes between a number of sublayers of AABW reflecting different source regions in the Weddell Sea and other circumpolar domains. While Reid et al. [1977] differentiate between density classes, in more recent studies the spreading of bottom water on neutral density surfaces is analyzed. For example, Orsi et al. [1999] separate AABW from overlying Circumpolar Deep Water (CDW) by the neutral density surface $\gamma^{\mathrm{n}}=28.27 \mathrm{~kg} \mathrm{~m}^{-3}$. For our purpose here it is sufficient to adopt the more traditional definition preferred by Speer and Zenk [1993]: Watermasses with $\theta<2{ }^{\circ} \mathrm{C}$ (AABW in a wider sense) are subdivided into two classes: Densest Weddell Sea Deep Water (WSDW) on the bottom and CDW above it separated by the $0.2^{\circ} \mathrm{C}$ isotherm. Speer and Zenk [1993] found that the bottom water transported across the Rio Grande Rise consists of about $40 \%$ WSDW in the density class $\geq 46.05 \sigma_{4}$ corresponding to the separating $0.2^{\circ} \mathrm{C}$ layer. Hence, WSDW characterizes the coldest watermass that reaches the Vema Channel on its equatorward pathway.

[11] Time series of potential temperature from the three spots along the Vema Channel displayed in Figure 1 as large circles are shown in Figure 2. The bulk of the data collected in the Vema Channel originates from the sill region. From the more northward located end of the Santos Plateau mouth we have data from five visits. Furthermore, the $\theta$ series from the Vema Extension with six visits round off the more complete series from the sill. Two of the three $\theta$ curves in Figure 2 are shifted upwards against the base curve (from

Table 1. Guidelines for the Evolution in CTD Calibration Uncertainties According to Robertson et al. [2002]

\begin{tabular}{lcc}
\hline \multicolumn{1}{c}{ Interval } & $\pm \Delta \theta / \mathrm{mK}$ & $\pm \Delta \mathrm{S}$ \\
\hline 1970 & 6 & 0.005 \\
$1980-1990$ & 3 & 0.003 \\
$1990-2000$, & 3 & 0.002 \\
WOCE standard & & \\
$>2000$, post-WOCE data & $2-3$ & $0.002-0.003$ \\
\hline
\end{tabular}

${ }^{\mathrm{a}}$ Here $\theta$ stands for potential temperature, and $\mathrm{S}$ stands for salinity. 


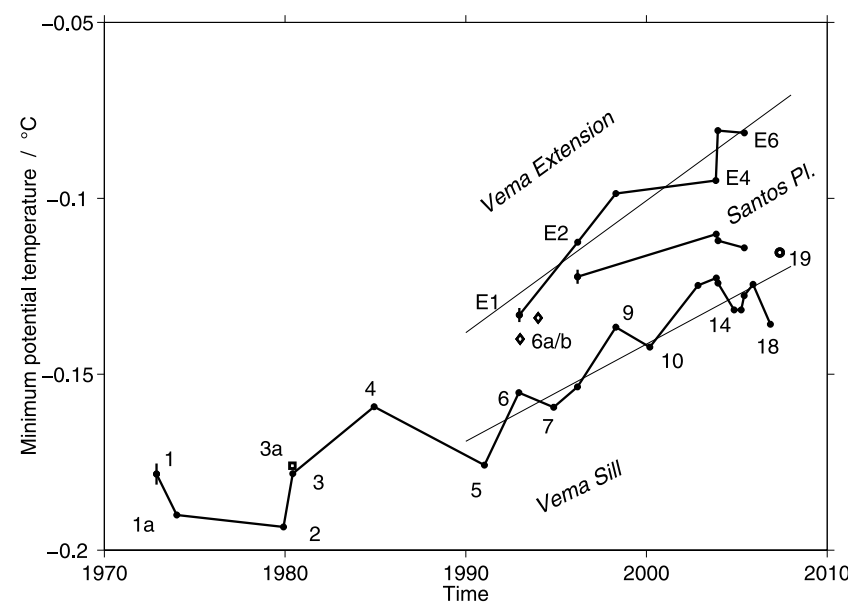

Figure 2. Evolution of potential temperature of the coldest Antarctic Bottom Water in the Vema Channel. Numbers 119 (sill region) and E1-E6 (extension) identify re-visits. The three locations under investigation are shown in Figure 1 by big circles. The two diamonds $(6 \mathrm{a} / \mathrm{b})$ display temperature observations with uncertainties in the minimal clearance from the bottom. The latest circle (19) represents preliminary data communicated after the acceptance date of the manuscript. The shown linear regression lines start in 1990. The square (3a) illustrates the first data point in the Santos Plateau series.

the sill). Natural averaged offsets of 25 and $39 \mathrm{mK}$ were obtained for the period 1990-2005. Within the statistical error range the implicit spatial increase in $\theta$ coincides reasonably with the horizontal temperature structure from a quasi-meridional section in November 2003. From the sequence of temperature minima of WSDW along the Vema Channel we infer by linear regression a horizontal temperature gradient of $\sim 5.7 \cdot 10^{-8} \mathrm{~K} \mathrm{~m}^{-1}$. Assuming pathway lengths of 220 and $760 \mathrm{~km}$ between the sill position and the downstream sites (circles in Figure 1) one expects a spatially conditioned offset in $\theta$ of $\sim 13$ and $\sim 43 \mathrm{mK}$. The difference between the two salinity curves (not shown here) comprises the latitudinal increase of near-bottom salinity of $\sim 2 \cdot 10^{-9} \mathrm{~m}^{-1}$. The salinity signal however is noisier than the temperature signal. Nevertheless, we note a density compensating horizontal correlation between $\theta$ and $\mathrm{S}$ along the flow path of WSDW.

[12] Next we investigate the temporal evolution of the coldest WSDW along the Vema Channel in more detail. Hogg and Zenk [1997] had analyzed the first part of the record already. They discussed in detail at least 14 visits to the Vema Channel with quality hydrographic measurements until 1996. Eleven datasets of the total 14 measurements were judged successful. The others had to be excluded because they did not meet the criteria for the cold core of WSDW in the Vema Channel. They either sampled not deep enough or at sub-optimal locations in view of large crosschannel gradients in $\theta$. Because $\theta$ from 1984 was judged as too high this data point was excluded from the earlier study. The sequence of salinities however shows no conspicuous outlier within the error bars for 1984. Because temperature is one parameter for the salinity calculation we tend to trust the $1984 \theta$ observation as well although some uncertainty remains in the $\theta-\mathrm{S}$ space (shown in Figure 3).

[13] In the initial paper dedicated to the flow of AABW in the Vema Channel, Zenk and Hogg [1996] found little variation of the coldest $\mathrm{AABW}$ passing through different pathways across the Rio Grande Rise until 1990. In the Vema Channel fluctuations were smaller than $5 \mathrm{mK}$, i.e. within the accuracy limits according to Table 1 . After such stagnant temperatures over 20 years a change of $+30 \mathrm{mK}$ in the interval 1991/1992 was rated as "quite significant".

[14] In a new quantification effort of mean properties and their variability in Table 2 we discriminate between different regions and intervals. As expected due to the shortness of the available time series the linear slope of the observed temperature rise depends strongly on the length of the selected interval. The annual temperature increase based on our measurements near the Vema Sill is a few millikelvin. Usually time gradient of temperature is in the range $2-3 \mathrm{mK} \mathrm{yr}^{-1}$ (though with occasional fluctuations of

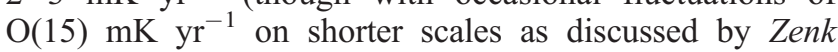
and Hogg [1996]). While $\theta$ rises systematically over three decades the overall series in salinity begin to show a negative tendency of $-0.3--1.2 \cdot 10^{-4} \mathrm{yr}^{-1}$. The associated density $\left(\sigma_{4}\right)$ decrease measures about $-0.4 \mathrm{~g} \mathrm{~m}^{-3} \mathrm{y}^{-1}$.

\section{Discussion}

[15] Our new results on increasing minimal temperatures in the Vema Channel are substantially more robust and confirm the previously reported rising trend. At the present state and in view of intrinsic instrumental errors we have to admit that the observed salinity changes are frequently within the accuracy of observations. However, with more planned visits to the Vema Channel, we hope in the future to be able to confirm or disprove the recognizable anticorrelated trends in salinity and density. The circles and

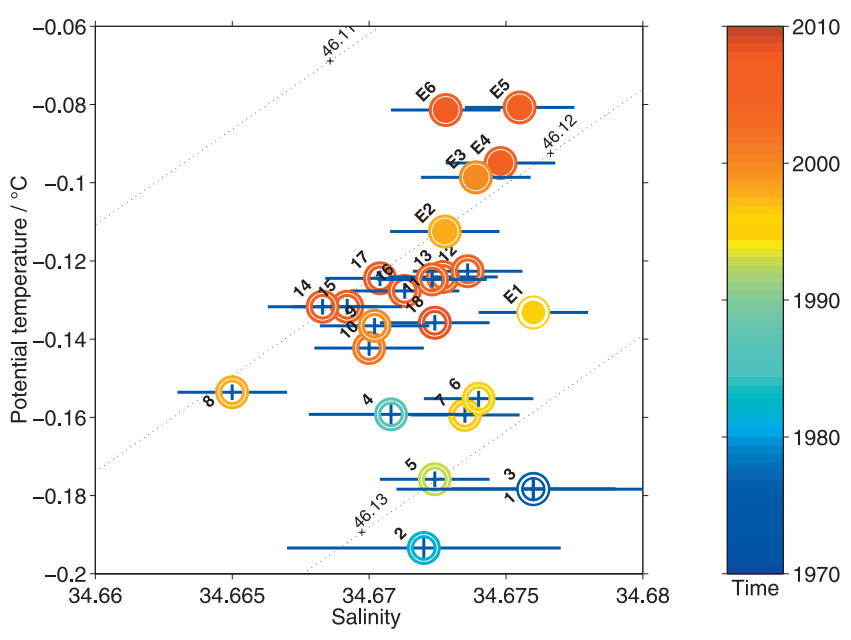

Figure 3. Potential temperature versus salinity diagram from the Vema Sill 1972-2006 (circles) and from the Vema Extension 1992-2005 (dots with annotation E). Dashed lines represent isopycnals $\left(\sigma_{4}\right)$ in $\mathrm{kg} \mathrm{m}^{-3}$ referenced to 4000 dbar. Cross wires give estimates of parameter accuracy. They decline in size with progressing time (see Table 1). 
Table 2. Means and Slopes (Drifts) of Hydrographic Near-Bottom Parameters From Three Locations Within the Vema Channel According to Figure $1^{\mathrm{a}}$

\begin{tabular}{|c|c|c|c|c|c|}
\hline & \multicolumn{5}{|c|}{ Intervals of Observations } \\
\hline & \multicolumn{2}{|c|}{ Vema Sill } & \multicolumn{2}{|c|}{$\begin{array}{c}\text { Santos Plateau Mouth } \\
\end{array}$} & \multirow{2}{*}{$\frac{\text { Vema Extension }}{1991-2005}$} \\
\hline & $1972-2006$ & $1991-2006$ & $1980-2005$ & $1996-2005$ & \\
\hline Number of Temperature profiles & 19 & 13 & 5 & 4 & 6 \\
\hline Number of salinity profiles & 18 & 13 & 4 & 3 & 6 \\
\hline $\begin{array}{l}\theta_{\min } \pm \mathrm{std} /{ }^{\circ} \mathrm{C} \\
\text { Salinity @ } \theta_{\min } \\
\sigma_{4} @ \theta_{\min } / \mathrm{kg} / \mathrm{m}^{3}\end{array}$ & $\begin{array}{l}-0.1475 \pm 0.0225 \\
34.6717 \pm 0.0027 \\
46.125 \pm 0.005\end{array}$ & \begin{tabular}{l}
\multicolumn{1}{c}{ Means } \\
$-0.1390 \pm 0.0162$ \\
$34.6711 \pm 0.0025$ \\
$46.123 \pm 0.003$
\end{tabular} & $\begin{array}{l}-0.1269 \pm 0.0278 \\
34.6736 \pm 0.0021 \\
46.123 \pm 0.005\end{array}$ & $\begin{array}{l}-0.1147 \pm 0.005 \\
34.6735 \pm 0.0025 \\
46.121 \pm 0.002\end{array}$ & $\begin{array}{l}-0.1002 \pm 0.020 \\
34.6743 \pm 0.0014 \\
46.119 \pm 0.004\end{array}$ \\
\hline $\begin{array}{l}\theta / \mathrm{mK} / \mathrm{yr} \\
\mathrm{Salinity} / 10^{-4} / \mathrm{yr} \\
\sigma_{4} / \mathrm{g} / \mathrm{m}^{3} / \mathrm{yr}\end{array}$ & $\begin{array}{l}+1.97 \\
-1.19 \\
-0.40 \\
\end{array}$ & $\begin{array}{l}+2.76 \\
-0.50 \\
-0.46 \\
\end{array}$ & $\begin{array}{l}+2.60 \\
-0.30 \\
-0.44 \\
\end{array}$ & $\begin{array}{l}+1.15 \\
(-25.7) \\
(-1.68) \\
\end{array}$ & $\begin{array}{l}+3.75 \\
-0.55 \\
-0.64\end{array}$ \\
\hline
\end{tabular}

${ }^{\text {a }}$ Here $\theta$ stands for potential temperature, std for standard deviation, and $\sigma_{4}$ potential density parameter referenced to $4000 \mathrm{~m}$. The two intervals from the Vema Sill refer to the total series from 1972-2006, and those starting with the significant warming onset in the early 1990 s until today. Two intervals are also given comparably for the mouth region with less optimal data coverage (and partly insignificant results labeled by brackets).

dots in the $\theta / \mathrm{S}$ diagram in Figure 3 evolve in time as expressed in the color code. They demonstrate a step by step transition from a colder and saltier to a warmer and slightly fresher state. The pertinent decrease in density is obvious from the overlaid isopycnals.

[16] Although Coles et al. [1996] reported a freshening of bottom water upstream in the northwest corner of the Argentine Basin, Hogg and Zenk [1997] were unable to find a significant change in salinity within the initial part of the available time series. Reid et al. [1977] had already discussed no spatial variations in the $\theta / \mathrm{S}$ relation along isopycnals. For example, on the $46.13 \sigma_{4}$ level they reported variations of 0.02 in salinity, which exceeded the corresponding temporal change ( 0.008 in a decade) of Coles et al. [1996] by a factor of $>2$.

[17] In search for the cause of the decadal upward thermal trend with indications for a freshening we trace WSDW backwards to its source region in the eastern Weddell Gyre. This densest water of the Argentine Basin spreads in an abyssal pathway along the continental slope off Patagonia and beyond as a contour current $(>4000 \mathrm{~m})$ before it reaches the southern entrance of the Vema Channel [see Orsi et al., 1999, Figure 6]. In a composite vertical $\theta$ section along the South Sandwich Trench, Locarnini et al. [1993] show rising Circumpolar Deep Water (CDW) south of the polar front at the southern boundary of the Antarctic Circumpolar Current (ACC) jointly with the northern most entrainment of Weddell Sea Bottom Water $\left(\theta<-0.7^{\circ} \mathrm{C}\right)$ southeast of South Georgia. Beyond this location WSDW $\left(-0.7^{\circ}<\theta<0.2^{\circ} \mathrm{C}\right)$ rises southwestward up to over $1000 \mathrm{~m}$. Sporadic winter time convection in the eastern Weddell Gyre can ventilate this critical water mass and stamp it with changing surface conditions. Many years later different vintages of WSDW will arrive at the Vema Sill. Calculations by Smythe-Wright and Boswell [1998] based on WOCE chlorofluorocarbon estimates indicate that the time scale of the abyssal circulation in the Argentine Basin is approximately 30 years. The implicit oceanic response time attends variations in abyssal watermass characteristics delayed and modified by vertical mixing with overlying warmer water [Zenk, 2007].
[18] A most relevant observation was published by Robertson et al. [2002]. On the basis of data from 1912 to 2000 they found in the eastern Weddell Sea, i.e. at the source of WSDW, indications for a slightly rising temperature in $1500-3500 \mathrm{~m}$ depth. The weak temperature signal seemed to be not or insignificantly compensated by salinity. The problem of how far the cause of warming is related to changes in the seasonal cooling process or to advection, modulated by the Weddell Front remains open in this study.

[19] Is the world ocean warming? This provocative question was recently raised once more by Harrison and Carson [2007]. From a global perspective the authors investigated subsurface temperature trends in the upper $500 \mathrm{~m}$ of the better sampled parts of the oceans between 1950 and 2000 . South of $20^{\circ} \mathrm{S}$ where the data coverage does not allow even for a statistical significance of less then $90 \%$ their determination of multi-decadal trend variability with a $2^{\circ} \times 2^{\circ}$ horizontal resolution fails. This topical example demonstrates the pressing need for a sustained ocean observing system. While the promising implementation of such a system for the upper and intermediate parts of the world ocean is underway (i.e. ARGO floats cycling down to $2000 \mathrm{~m}$ ) a comparable collection of abyssal parameters is extremely rare. With the three-dimensional thermohaline circulation in mind, oceanic choke points like the Vema Channel are obvious sites where decadal trends are accessible for in-situ observations. We strongly encourage sustained observations of interbasin exchanges of cold bottom water masses in globally distributed key locations. While writing this note from the South Atlantic we learned about a comparable abyssal temperature change in the western North Atlantic analyzed by Cunningham and Alderson [2007]. However, their rate $\left(-2.1 \mathrm{mK} \mathrm{yr}^{-1}\right)$ has a different sign. They observed a decadal cooling in the northern most extensions of AABW based on zonal averages along $24.5^{\circ} \mathrm{N}$ between $65^{\circ}-75^{\circ} \mathrm{W}$ in five repeated hydrographic sections (1957-2004). A reconciling explanation for the different signs in the observed abyssal temperature trends in the South and North Atlantic is needed. 
[20] Acknowledgments. In Germany this work has been partially funded by the Bundesministerium für Bildung und Forschung, Berlin, and the Deutsche Forschungsgemeinschaft, Bonn. The Russian cruises were supported by the Meridian program (NWO-RFBR grant 047.017. 2006.003). We appreciate constructive suggestions from two anonymous reviewers.

\section{References}

Coles, V. J., M. S. McCartney, B. D. Olson, and W. J. Smethie Jr. (1996), Changes in Antarctic Bottom Water properties in the western South Atlantic in the late 1980s, J. Geophys. Res., 101(C4), 8957-8970.

Cunningham, S. A., and S. Alderson (2007), Transatlantic temperature and salinity changes at $24.5^{\circ} \mathrm{N}$ from $195-2004$, Geophys. Res. Lett., doi:10.1029/2007GL029821, in press.

Fukasawa, M., H. Freeland, R. Perkin, T. Watanabe, H. Uchida, and A. Nishina (2004), Bottom water warming in the North Pacific Ocean, Nature, 427, 825-827.

Harrison, E. D., and M. Carson (2007), Is the world ocean warming? Upper ocean temperature trends, 1950-2000, J. Phys. Oceanogr., 37, 174-187.

Hogg, N. G., and W. Zenk (1997), Long-period changes in the bottom water flowing through Vema Channel, J. Geophys. Res., 102(C7), 15,63915,646 .

Johnson, G. C., and T. B. Sanford (1992), Secondary circulation in the Faroe Bank Channel outflow, Prog. Oceanogr., 22, 927-933.

Jungclaus, J. H., and M. Vanicek (1999), Frictionally modified flow in a deep ocean channel: Application to the Vema Channel, J. Geophys. Res. 104(C7), 21,123-21,136.
Locarnini, R. A., T. Whitworth III, and W. D. Nowlin Jr. (1993), The importance of the Scotia Sea on the outflow of Weddell See Deep Water, J. Mar. Res., 51, 135-153.

Orsi, A. H., G. C. Johnson, and J. L. Bullister (1999), Circulation, mixing, and production of Antarctic Bottom Water, Prog. Oceanogr., 43, 55-109.

Reid, J. L., W. D. Nowlin Jr., and W. C. Patzert (1977), On the characteristics and circulation of the southwestern Atlantic Ocean, J. Phys. Oceanogr., 7, 62-91.

Robertson, R., M. Visbeck, A. Gordon, and E. Fahrbach (2002), Long-term temperature trends in the deep waters of the Weddell Sea, Deep Sea Res., Part II, 49, 4791-4806.

Smythe-Wright, D., and S. Boswell (1998), Abyssal circulation in the Argentine Basin, J. Geophys. Res., 103(C8), 15,845-15,851.

Speer, K. G., and W. Zenk (1993), The flow of Antarctic Bottom Water into the Brazil Basin, J. Phys. Oceanogr., 23, 1289-1303.

Zenk, W. (2007), Temperature fluctuations and current shear in Antarctic Bottom Water at the Vema Sill, Prog. Oceanogr., in press.

Zenk, W., and N. Hogg (1996), Warming trend in Antarctic Bottom Water flowing into the Brazil Basin, Deep Sea Res., Part I, 43, 1461-1473.

Zenk, W., K. G. Speer, and N. G. Hogg (1993), Bathymetry at the Vema Sill, Deep Sea Res., Part I, 40, 1925-1933.

E. Morozov, Shirshov Institute of Oceanology, Moscow, Russia. (egmorozov@mail.ru)

W. Zenk, Leibniz Institute of Marine Sciences at the University of Kiel (IFM-GEOMAR), D-24105 Kiel, Germany. (wzenk@ifm-geomar.de) 